\title{
Treatment with a topical glucocorticoid, budesonide, reduced the variability of rhinomanometric nasal airway
} resistance*

\author{
Helle L. Thulesius', Anders Cervin², Max Jessen \\ 'Department of Oto-Rhino-Laryngology, Head and Neck Surgery, Växjö Central Hospital, Sweden \\ 2Department of Oto-Rhino-Laryngology, Head and Neck Surgery, Lund University, Sweden
}

Rhinology 52: 19-24, 2014

DOI:10.4193/Rhino12.180

*Received for publication:

November 1, 2012

Accepted: August 16, 2013

\begin{abstract}
Background: Previous rhinomanometry studies have shown significant long-term variability of the nasal airway resistance and questioned the clinical validity of rhinomanometry.
\end{abstract}

Research question: Could treatment with a topical glucocorticoid, budesonide, influence the long-term variability of active anterior rhinomanometry?

Methods: Eight healthy volunteers participated in an unblinded controlled trial without, and later with, nasal budesonide once a day for 5 months. Their nasal airway resistance was measured every two weeks with active anterior rhinomanometry before and after decongestion with xylometazoline hydrochloride. In addition, subjective nasal obstruction was evaluated on a Visual Analogue Scale before each measurement. The participants had a year earlier been investigated with rhinomanometry every two weeks during 5 months but without budesonide treatment. We compared the variability of nasal airway resistance during the two periods with and without treatment with topical budesonide.

Results: Budesonide significantly reduced mean nasal airway resistance and the standard deviation of the mean after decongestion for 6 of 8 participants. The mean reduction of the nasal airway resistance was $40 \%$ for the decongested nasal cavity compared to the period without treatment with nasal budesonide. Subjective nasal obstruction assessed by Visual Analogue Scale was reduced in 3 of the 8 participants.

Conclusion: The variability of nasal airway resistance was significantly reduced by treatment with topical budesonide for 6 out of 8 healthy volunteers participating in an unblinded repeated 5 month trial where the participants served as their own controls.

Key words: rhinomanometry, nasal airway resistance, topical nasal glucocorticoid, xylometazoline, budesonide

\section{Introduction}

Rhinomanometry is a tool for measuring nasal airway resistance (NAR) by registering flow and pressure fall through the nasal cavity. In a previous study, we showed that the rhinomanometric NAR has high long term variability ${ }^{(1)}$.

NAR is determined on the basis of swelling and constriction of the erectile tissue at the inferior turbinate and at the nasal septum ${ }^{(2)}$. The a2-adrenoreceptor agonists xylometazoline and oxymetazoline, which are recommended by the Internati- onal Standardization Committee of Rhinomanometry (ISCR) as decongestants in rhinomanometry, produce both reduction in mucosal blood volume and blood flow ${ }^{(3-5)}$.

Intranasally administered glucocorticoid with no or little systemic effects was introduced in $1973^{(6)}$. Because of its multitude of anti-inflammatory effects, it has become an established therapy for nasal disorders such as nasal polyposis, allergic and non-allergic rhinitis. The side effects are usually minor. Septal perforation and ulcers in the nose are rare adverse effects ${ }^{(7)}$. The onset 
of action is within 4-12 hours after administration, but maximal efficacy is achieved within a few days ${ }^{(8)}$. Topical glucocorticoids have been used for 40 years, but their mode of action is still inadequately understood.

When glucocorticoids are applied to the skin, a "vasoconstriction" visible as a blanching phenomenon is seen after a few hours, known as the McKenzie test ${ }^{(9)}$. The extent of blanching is used to grade the glucocorticoid potency. We would expect the same reaction in the nasal mucosa. However, Bende et al. found no significant differences in the mucosal blood flow using the ${ }^{133}$ Xe wash-out method after a one week administration of nasal budesonide as compared with placebo ${ }^{(10)}$. Cervin et al. showed similar results after only one dose $(64 \mu \mathrm{g})$ of intranasal budesonide by measuring the mucosal blood flow with Laser Doppler flowmetry after 20 minutes ${ }^{(11)}$. It seems likely that a more complex process than vasoconstriction is responsible for the clinical effect of nasal glucocorticoids ${ }^{(12,13)}$.

Rhinomanometry is often used in the decision making process for nasal surgery ${ }^{(14,15)}$. In the general population there is a high frequency of septal deviations, with prevalence figures of over $50 \%$, and most are non-symptomatic and non-traumatic ${ }^{(16)}$. The patients' symptoms often do not concur with the NAR ${ }^{(17,18)}$. Therefore, it is important that the rhinomanometric NAR is reliable to help the surgeon make the right decision about nasal surgery. From the Swedish ENT quality register (http://kvalitet. onh.nu/), we found that only $76 \%$ (range from different centres 40-100\%) of 3877 patients (2008-2010) were satisfied with their septal surgery six months postoperatively.

We hypothesize that one reason for the long-term variability of NAR could be a subclinical nasal mucosal inflammation giving an insufficient decongestion with $0.1 \%$ xylometazoline hydrochloride during rhinomanometric measurements. Hence, the aim of this study was to investigate if it was possible to reduce the long-term variability of the NAR measured with active anterior rhinomanometry by treatment with the nasal glucocorticoid budesonide.

\section{Materials and methods}

\section{Patient population}

Eight healthy volunteers ( 6 women, 2 men, ages 42-64, mean 55 years) signed an informed consent form and all had a rhinoscopy and a standard skin prick test for allergy (alder, hazel, birch, timothy, mugwort, house dust mites, moulds and pets) before study start. None of the participants had any subjective allergic symptoms, but one participant (no. 3) had a minor positive reaction to grass (timothy) in the skin prick test. One participant was a cigarette smoker (no. 5). Two had a deviated nasal septum (nos. 7 and 8) and six participants had a reasonably straight septum according to rhinoscopy. No widely accepted objective classification of septal deviation has been developed for routine use $^{(19,20)}$

\section{Rhinomanometry}

In our previous study, 9 participants did 10-15 active anterior rhinomanometries during 5 months, at 2 week intervals from late autumn to early spring to test the long-term reproducibility of NAR. Eight of those 9 people participated in the present study, and one had moved. The participants treated themselves with the topical glucocorticoid budesonide (Rhinocort ${ }^{\circledast}$, AstraZeneca) once a day. Seven preferred nasal spray $(2 \times 64 \mu \mathrm{g})$, and one preferred nasal powder in a Turbuhaler ${ }^{\circledast}(2 \times 100 \mu \mathrm{g})$ in each nostril. During a 5-month period from November to March the 8 participants again did 10 active anterior rhinomanometries at 2 week intervals. We performed the rhinomanometric measurements according to the ISCR at the same time of day for each individual ${ }^{(17,18)}$. Before the rhinomanometries, all participants were acclimatized in the examination room at $21^{\circ} \mathrm{C}$ and $50 \%$ relative humidity for at least 30 minutes. They had alcohol, nicotine and caffeine restrictions 4 hours before each measurement. We calibrated the rhinomanometer (Rhino Comp ${ }^{\oplus}$, Sweden) once a day before the first measurement. The same equipment was used by the same well trained nurses who performed all the measurements in both studies. The pneumotachograph was checked by connecting a metal artificial nose to the built-in calibration pump. Calibration continued until measurements gave values determined by the manufacturer. The equipment was tested regularly by our medical technical department. The anterior active rhinomanometry was performed before and after decongestion of the nasal mucosa with administration of two puffs $(0.28 \mathrm{ml})$ of xylometazoline hydrochloride $1 \mathrm{mg} / \mathrm{ml}$ (Otrivin ${ }^{\circledR}$, Novartis) into each nasal cavity followed by one extra puff $(0.14 \mathrm{ml})$ in each nasal cavity 7-8 minutes later, thus a total of $0.42 \mathrm{ml}(420 \mu \mathrm{g})$ of xylometazoline in each nasal cavity ${ }^{(21)}$. After the participants had gently blown the nose, the rhinomanometry was repeated 15 minutes after the first spray dose. A transparent nose mask was used, and one nostril was sealed with adhesive tape for the pressure recording. The flow was obtained from the other cavity with the pneumotachograph. NAR values for the right and left nasal cavities were obtained on each occasion and values for the total nose were calculated from the individual cavities. NAR was represented in v2 values as previously outlined by Broms (22). The relevant NAR is $\mathrm{R} 2=\tan \mathrm{v} 2$.

Statistical evaluation was based on $\mathrm{v} 2$, an angle that varies between 0 and 90 degrees and is calculated from a point on the whole curve where it intersects a circle with a radius of $200 \mathrm{~Pa}$ on the abscissa and $200 \mathrm{~cm}^{3} / \mathrm{sec}$ on the ordinate (Figure 1) ${ }^{(23)}$. All curves reach the circle and therefore $\mathrm{v} 2$ can be calculated from all curves. Resistance at $150 \mathrm{~Pa}, \mathrm{R} 150$, can be calculated from R2. NAR can be given as resistance $R$ at 150 Pa or as $v 2$ according to ISCR and the con-sensus report on acoustic rhinometry and 


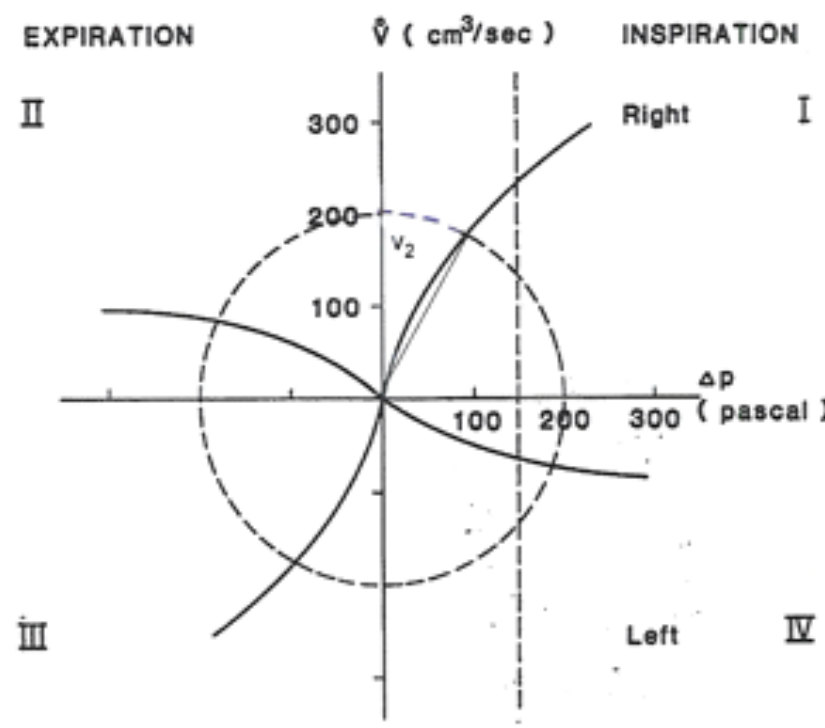

Figure 1. Broms' model for active anterior rhinomanometry: $\mathrm{v} 2$ is the angle between the flow axis and a line through the origin to the point where the $\Delta \mathrm{p} / \mathrm{V}^{\circ}$-curve intersects a circle with a radius of 200 (200 Pascal or $\left.200 \mathrm{~cm}^{3} / \mathrm{s}\right)$. This expresses the nasal airway resistance NAR ( $R 2=\tan$ $\mathrm{v} 2)$, i.e. $\mathrm{v} 2=20^{\circ}$ correspond to $\mathrm{R} 2=0.36 \mathrm{~Pa} /\left(\mathrm{cm}^{3} / \mathrm{s}\right)$ and $\mathrm{R} 150=0.48 \mathrm{~Pa} /$ $\left(\mathrm{cm}^{3} / \mathrm{s}\right)$. Another approach according to the committee report on standardization of rhinomanometry is to express the resistance at a fixed pressure of 150 Pascal, R150.

rhinomanometry ${ }^{(17,18)}$. The normal mean v2 value $(+\mathrm{SD})$ for the decongested mucosa is $13.1+6.8$ degrees, $\mathrm{R} 2=0.23 \mathrm{~Pa} /\left(\mathrm{cm}^{3} / \mathrm{s}\right)$ and $\mathrm{R} 150=0.36 \mathrm{~Pa} /\left(\mathrm{cm}^{3} / \mathrm{s}\right)^{(21)}$. The upper $95 \%$ confidence limit was taken as maximum normal value accord-ing to Broms (24). Each participant was asked to assess the degree of nasal stuffiness before each rhinomanometry on a $100 \mathrm{~mm}$ VAS scale. VAS $0 \mathrm{~mm}$ implied a completely free nose, and $100 \mathrm{~mm}$ a completely blocked nose. We compared the reproducibility for the two test periods regarding mean $\mathrm{v} 2$, standard deviation, median VAS and coefficient of variation CV for the NAR for each participant.

The study was approved by Linköping University Ethical Review Board.

\section{Statistical analysis}

The results were analysed using the SPSS version 20.0 software for Windows. Statistical analysis was carried out using Student's t-test to compare the v2-means, and the F-test to compare their variances (SD2). Differences in VAS between the two test periods were tested with the Mann-Whitney test. We used Gauss approximation to assess the variance of the rela-tive chance in v2. A p value $<0.05$ was considered statistically significant. The coefficient of variation (CV) was used to test the reproducibility of the rhinomanometric measurements.
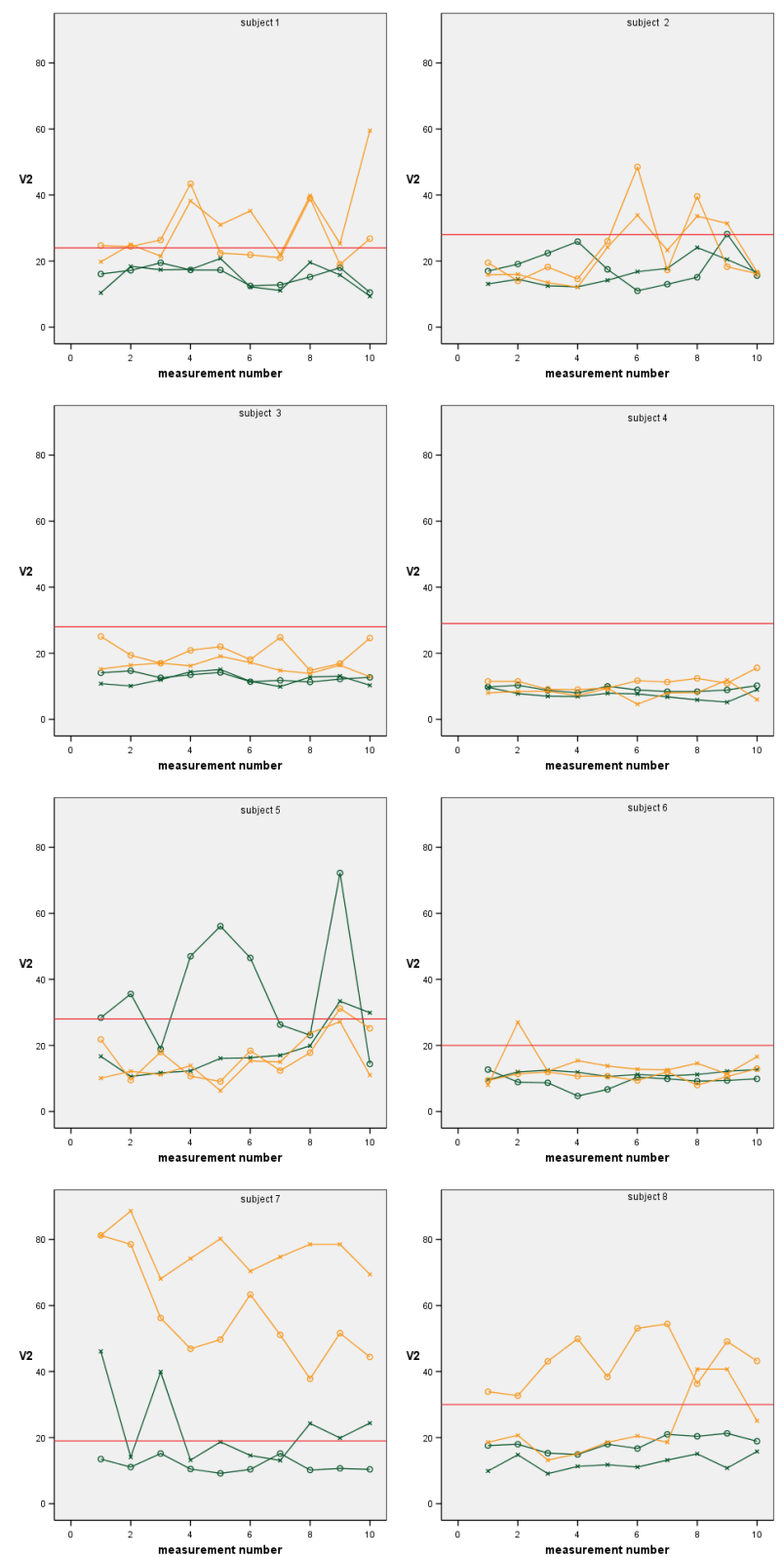

Figure 2. The decongested NAR ( 22 on the $y$-axis and measurement number on the x-axis) from the rhinomanometries of the 8 participants. The green lines (right and left) are NAR during treat-ment with topical budesonide spray, and the yellow lines (right and left) are NAR without budesonide treatment. The horizontal line is the limit (upper $95 \% \mathrm{Cl}$ ) for normal values according to Broms and corrected for the height of the subject.

\section{Results}

The results for each participant are summarized in Figure 2 and 3 and Table 1 . We found no correlation between difficulties in decongesting the nasal mucosa with xylometazoline and any particular season or time of year. None of the participants showed any sign of becoming habituated to rhinomanometry during the investigations. 

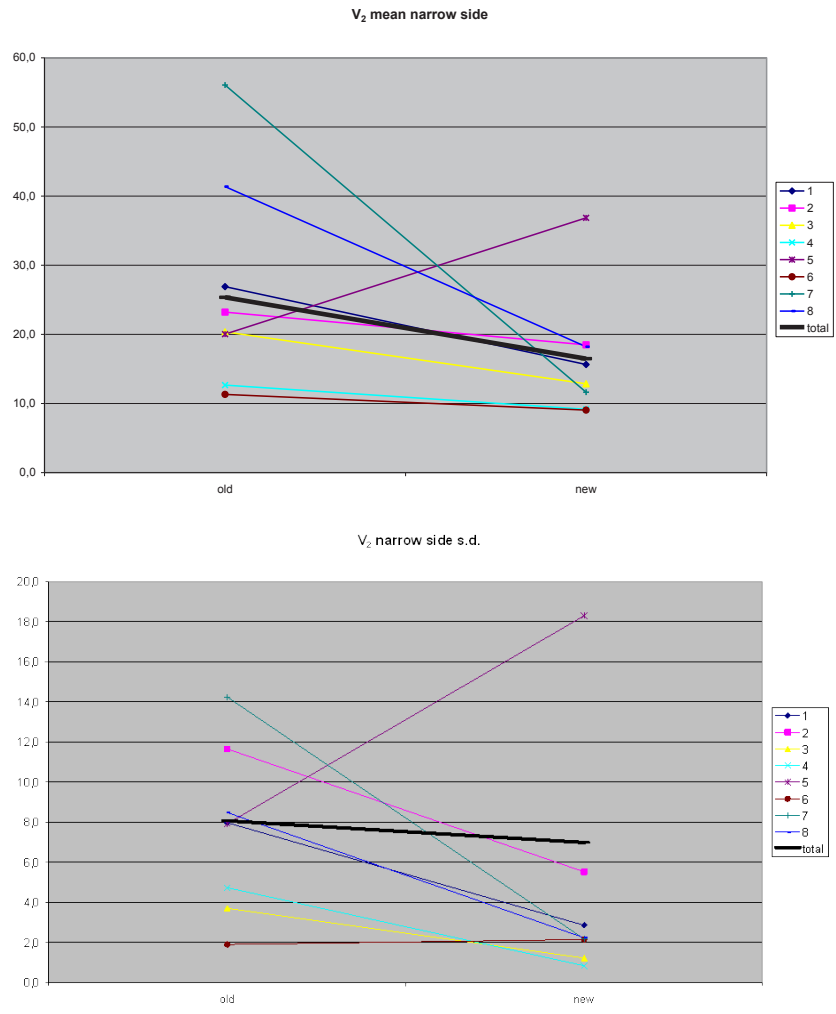

Figure 3. Change in mean for v2 and s.d. (standard deviation) after decongestion for each person (the narrow side of the nasal cavity), old: from the old study without budesonide and new: from this study with budesonide.

Table 1. The results from each of the 8 participants from the narrowest side of the decongested nasal cavity. GCS: glucocorticosteroids. CV: coefficient of variation (CV in brackets is without GCS). n.s.: non significant. \% diff: ((mean v2 - GCS) - (mean v2 + GCS)) / (mean v2 - GCS). We used Gauss approximation to assess the variance of the relative chance in $\mathrm{v} 2$.
The mean value for $\mathrm{v} 2$ and the standard deviation (SD) of the mean $v 2$ decreased significantly $(p<0.05)$ for 6 of the 8 participants, when they used nasal budesonide during a 5 month test period compared to a similar test period without budesonide treatment. The mean v2 decreased $25 \%$ for the undecongested nose and $40 \%$ for the decongested nose. For participant no. 5 , one side of the nose developed a higher mean $\mathrm{v} 2$ and an increased SD during the period with budesonide treatment. Participant no. 6 already had a low SD in the first period without budesonide, and SD was not significantly decreased after budesonide treatment.

Five participants did 10 test-retest rhinomanometries on the same day in order to test the short-time reproducibility of NAR, with a resulting $\mathrm{CV}$ of $8-17 \%$. During the 5 -month test period with budesonide, the $\mathrm{CV}$ range for the decongested NAR was 8-50\% and mean CV 19\% compared to the measurements without budesonide, where the mean CV was $27 \%$ and the range 8-53\%.

The median VAS was significantly decreased for participants no. 6,7 and 8 when the two test periods with and without topical budesonide were compared $(p<0.05)$.

\section{Discussion}

In this unblinded study, 8 subjects acted as their own controls by doing rhinomanometric measurements every two weeks during two 5 month periods with and without nasal glucocorticoid treatment. Budesonide seemed to stabilise the nasal mucosa. Rhinomanometric NAR values were lower and varied less over time after treatment with budesonide than NAR from the nasal cavity decongested with xylometazoline only.

\begin{tabular}{|c|c|c|c|c|c|c|}
\hline $\begin{array}{c}\text { Subject } \\
\text { No. }\end{array}$ & $\begin{array}{l}\text { septum } \\
\text { shape }\end{array}$ & $\begin{array}{c}\text { mean v2 } \pm \text { SD } \\
\text { narrow side } \\
\text { - GCS }\end{array}$ & $\begin{array}{c}\text { mean v2 } \pm \text { SD } \\
\text { narrow side } \\
+\mathrm{GCS}\end{array}$ & $\begin{array}{c}\% \\
\text { mean-diff } \\
\text { narrow side }\end{array}$ & $\begin{array}{c}\% \\
\text { SD-diff } \\
\text { narrow side }\end{array}$ & $\begin{array}{c}\text { CV } \\
\text { Narrow side }\end{array}$ \\
\hline 1 & straight & $28 \pm 8$ & $16 \pm 3$ & 43 & 63 & $18(30)$ \\
\hline 2 & straight & $23 \pm 12$ & $19 \pm 6$ & 17 n.s. & 50 & $30(53)$ \\
\hline 3 & straight & $20 \pm 4$ & $13 \pm 1$ & 35 & 75 & $9(20)$ \\
\hline 4 & straight & $13 \pm 5$ & $9 \pm 1$ & 31 & 80 & 9 (39) \\
\hline 5 & straight & $20 \pm 8$ & $37 \pm 18$ & -85 n.s. & -125 n.s. & $50(40)$ \\
\hline 6 & straight & $11 \pm 2$ & $9 \pm 2$ & 18 & 0 n.s. & $8(29)$ \\
\hline 7 & deviation & $56 \pm 14$ & $12 \pm 2$ & 79 & 86 & $19(25)$ \\
\hline 8 & deviation & $41 \pm 8$ & $18 \pm 2$ & 56 & 75 & $12(20)$ \\
\hline
\end{tabular}


From our previous study on the reproducibility of NAR over 5 months without nasal glucocorticoids, the CVs for the repeated measurements every second week varied $8-53 \%$, and the CV median was $27 \%{ }^{(1)}$. The CV median for NAR in the present study during long-term budesonide treatment was 19\% but the range was still high, $8-50 \%$. This was due to the fact that both the mean $\mathrm{v} 2$ and the SD of the mean $\mathrm{v} 2$ decreased (CV $=100 \times \mathrm{SD} /$ mean).

The reproducibility of a clinical measurement depends on equipment reliability, the skill of the performer, patient cooperation, and real variation in the measured parameter. As for this study, we performed the procedure strictly according to the guidelines from the ISCR ${ }^{(4,5)}$. The equipment was carefully calibrated daily according to the manufacturer's guidelines. The performers were well trained nurses with decades of experience of rhinomanometry. Broms' limit values, the upper $95 \% \mathrm{Cl}$, are NAR values from the nasal cavity decongested by physical exercise on a bicycle ergometer to a heart rate of $150 /$ minute ${ }^{(23)}$. Jessen and Malm showed in 1988 that spraying $0.1 \%$ xylometazoline hydrochloride twice, 7-8 minutes apart, gave a better decongestion than exercise and other modes of pharmacological decongestion ${ }^{(21)}$. Therefore we used this method of decongestion in our study.

The participants in this study began the treatment with nasal budesonide one week prior to the first rhinomanometric measurement, and except for participant no. 5 even the first measurement showed a decrease in NAR.

The reproducibility of rhinomanometric measurements, both anterior and posterior, over a short period of time for groups of patients has been well studied ${ }^{(25-27)}$. In these studies, an acceptable short time reproducibility was found with CVs 7-15\%. The CVs for the 10 test-retests on the same day in our previous study was $8-17 \%$, thus an acceptable short term reproducibility ${ }^{(1)}$. The main difference between our two measurement periods was the daily status of the nasal mucosa and the pharmacologic decongestion specifically on the day of measurement.

In our regular clinical setting, only one rhinomanometric measurement is done for each patient before and after nasal decongestion with xylometazoline hydrochloride. The practical consequence of a false high NAR for the single nasal cavity could at worst be a surgical intervention. In contrast, a false normal NAR would not indicate a need for surgery, although surgery might improve the nasal airflow. Today, many patients have nasal surgery but the outcome is not always as good as we would expect ${ }^{(28)}$. On average, $24 \%$ of Swedish patients were not satisfied with the result of their septal surgery 6 months postoperatively (Swedish ENT-quality register 2008-2010). During this period, 3877 septoplasties were reported, and that means 930 operations did not get the expected outcome from the patients' point of view.

Figure 2 and 3 shows that also the participants with low NAR values without budesonide treatment (no 3,4 and 6) had less variable NAR after budesonide treatment. A difference that was significant. For participant no. 5, the only cigarette smoker, the topical nasal glucocorticoid did not decrease the mean NAR. One side of the participant's nasal cavity had a significantly higher NAR during budesonide treatment. This participant did not have septal deviation and had low NAR during the first test period without budesonide. Nicotine restrictions were limited to 4 hours before the measurement. Bozec et al. showed that NAR and VAS were significantly higher in a group of smokers as compared to a control group ${ }^{(29)}$. However, Thorvold et al. showed that smoking did not affect the physiological decongestion of the nasal mucosa after exercise ${ }^{(30)}$. Some authors found a less compliant nasal mucosa in smokers than in non-smokers ${ }^{(31)}$. The results of participant no. 7 are difficult to explain. During the first 5 month period without nasal glucocorticoids NAR was very high bilaterally with great variation. During the next 5 month period with glucocorticoid treatment, NAR decreased significantly on both sides of the nasal cavity and was even normalised on the wider side. No. 7 was the only participant who preferred budesonide in Turbuhaler ${ }^{\oplus}$. The amount of budesonide per puff of spray is $64 \mu \mathrm{g}$ and per inhalation with the Turbuhaler ${ }^{\otimes} 100 \mu \mathrm{g}$. So no. 7 was given a higher dose of budesonide. Could this big reduction of NAR be caused by treatment of a subclinical inflammation in the nasal mucosa ${ }^{(32)}$ ?

Although clinically effective, the precise mode of action of topical glucocorticoids in the treatment of non-allergic nasal obstruction has not been clarified. In this open study we found a significant decrease of NAR after one week of treatment with topical budesonide, and this effect was sustained during the five months of treatment. We are aware that we had a small number of participants so future studies on more subjects should be done to confirm our findings.

\section{Conclusions}

We have shown that topical nasal budesonide reduced rhinomanometric NAR and it's variability in an open before and after study where 8 clinically non-allergic volunteers acted as their own controls during a $5+5$ months trial. Yet, the nasal airway measured with active anterior rhinomanometry was still not totally decongested as a pure skeletal structure. There was still a variable mucosal component.

\section{Acknowledgement}

The authors wish to thank Anna Lindgren, PhD, Lund University for statistical assistance. The nasal steroid was kindly provided by AstraZeneca AB, Södertälje, Sweden. 


\section{Authorship contribution}

Substantial contributions to conception, design and acquisition of data were made by Thulesius and Jessen. Analysis and interpretation of data, drafting and revising of the article was done by all three authors together. The final approval of the article was determined by all three authors.

\section{Conflict of interest}

There was no conflict of interest in this study.

\section{References}

1. Thulesius HL, Cervin A, Jessen M. Can we always trust rhinomanometry? Rhinology. 2011, 49: 46-52.

2. Haight JS, Cole P. The site and function of the nasal valve. Laryngoscope. 1983, 93: 49-55.

3. Bende M. The effect of topical decongestant on blood flow in normal and infected nasal mucosa. Acta Otolaryngol. 1983, 96: 523-527.

4. Clement PA. Committee report on standardization of rhinomanometry. Rhinology. 1984, 22:151-155.

5. Clement PA, Gordts F. Consensus report on acoustic rhinometry and rhinomanometry. Rhinology. 2005, 43: 169-179.

6. Mygind N. Local effect of intranasal beclomethasone dipropionate aerosol in hay fever. Br Med J. 1973, 4: 464-466.

7. Cervin A, Andersson M. Intranasal steroids and septum perforation--an overlooked complication? A description of the course of events and a discussion of the causes. Rhinology. 1998, 36: 128-132.

8. Stern MA, Dahl R, Nielsen LP, Pedersen B and Schrewelius C. A comparison of aqueous suspensions of budesonide nasal spray (128 micrograms and 256 micrograms once daily) and fluticasone propionate nasal spray (200 micrograms once daily) in the treatment of adult patients with seasonal allergic rhinitis. Am J Rhinol. 1997, 11: 323330.

9. McKenzie A. Percutaneous absorbtion of steroids. Arch Dermatol. 1962, 86: 611

10. Bende M, Lindqvist N, Pipkorn U. Effect of a topical glucocorticoid, budesonide, on nasal mucosal blood flow as measured with 133Xe wash-out technique. Allergy. 1983, 38: $461-464$.

11. Cervin A, Akerlund A, Greiff $L$ and Andersson M. The effect of intranasal budesonide spray on mucosal blood flow measured with laser Doppler flowmetry. Rhinology. 2001, 39: 13-16.

12. Lindqvist N, Holmberg K, Pipkorn U Intranasally administered budesonide, a glucocorticoid, does not exert its clinical effect through vasoconstriction. Clin Otolaryngol Allied Sci. 1989, 14: 519-523.
13. Pipkorn U. Budesonide and nasal allergen challenge testing in man. Allergy. 1982, 37: 129-134.

14. Holmstrom M, Kumlien J. A clinical follow up of septal surgery with special attention to the value of preoperative rhinomanometric examination in the decision concerning operation. Clin Otolaryngol Allied Sci. 1988, 13: 115-120.

15. Holmstrom M. The use of objective meas ures in selecting patients for septal surgery. Rhinology. 2010, 48: 387-393.

16. Perez P, Sabate J, Carmona A, CatalinaHerrera CJ and Jimenez-Castellanos J. Anatomical variations in the human paranasal sinus region studied by CT. J Anat. 2000 197 (Pt 2): 221-227.

17. Thulesius H, Cervin A, Jessen M. The importance of side difference in nasal obstruction and rhinomanometry. Clin Otolaryngol. 2012; 37 (1): 17-22.

18. Andre RF, Vuyk HD, Ahmed A, Graamans K and Nolst Trenite GJ. Correlation between subjective and objective evaluation of the nasal airway. A systematic review of the highest level of evidence. Clin Otolaryngol. 2009, 34: 518-525.

19. Baumann IBH. A new classification of septal deviations. Rhinology. 2007, 45: 220-223.

20. Guyuron B UC, Scull H. A practical classification of septal deviation and an effective guide to septal surgery. Plast reconstr surg. 1999, 104: 2202-2209.

21. Jessen M, Malm L. Use of pharmacologic decongestion in the generation of rhinomanometric norms for the nasal airway. Am J Otolaryngol 1988, 9:336-340

22. Broms P, Jonsson B, Lamm CJ. Rhinomanometry.ll. A system for numerical description of the nasal airway resistance. Acta Otolaryngol. 1982, 94: 157-168.

23. Broms $P$, Ivarsson $A$, Jonson $B$ Rhinomanometry. I. Simple equipment. Acta Otolaryngol. 1982, 93: 455-460.

24. Broms P, Jonson B, Malm L. Rhinomanometry. IV. A pre- and postoperative evaluation in functional septoplasty. Acta Otolaryngol. 1982, 94: 523-529.

25. Sipila J, Suonpaa J, Laippala P. Evaluation of nasal resistance data in active anterior rhinomanometry with special reference to clinical usefulness and test-retest analysis. Clin Otolaryngol Allied Sci. 1992, 17: 170177.

26. Jessen M, Ivarsson A, Malm L. Nasal airway resistance after decongestion with a nasal spray or a bellows device. Rhinology. 1996, 34: 28-31.

27. Carney AS, Bateman ND, Jones NS. Reliable and reproducible anterior active rhinomanometry for the assessment of unilateral nasal resistance. Clin Otolaryngol Allied Sci. 2000, 25: 499-503.

28. Jessen $M$, Malm L. The importance of nasal airway resistance and nasal symptoms in the selection of patients for septoplasty. Rhinology. 1984, 22: 157-164.

29. Bozec A, Guevara N, Bailleux S, Lecoq M, Santini J and Castillo L. Evaluation of rhinologic signs among smokers. Ann Otolaryngol Chir Cervicofac. 2004, 121: 286291.

30. Thorvold $H$, Bende M. The effect of smoking on physiological decongestion of the nasal mucosa in human. Rhinology. 2010, 48: 438-440

31. Kjaergaard T, Cvancarova M, Steinsvaag SK. Smoker's nose: structural and functional characteristics. Laryngoscope. 120: $1475-$ 1480 .

32. Hellgren J, Yee BJ, Dungan G and Grunstein RR. Altered positional regulation of nasal patency in patients with obstructive sleep apnoea syndrome. Eur Arch Otorhinolaryngol. 2009, 266: 83-87.

Mrs Helle L. Thulesius, MD, PhD Department of Oto-Rhino-Laryngology, Head and Neck Surgery Växjö Central Hospital Sweden

Tel :+46-470-592285

Fax: +46-470-586295

E-mail: helle.l.thulesius@ltkronoberg. se 